\title{
Android Based Voice Activated Wheel Chair for Disabled
}

\author{
R.Mohana Priya, Indhulekha.B, Riya Johnson, Arun.V.N, R.Karthikeyan
}

\begin{abstract}
The aim of the project is to develop a wheel chair which can be controlled by voice of the person. It is based on the speech recognition model. The project is focused on controlling the wheel chair by human voice. The system is intended to control a wheel seat by utilizing the voice of individual. The structure of this framework will be particularly valuable to the crippled individual and furthermore to the older individuals. It is a booming technology which interfaces human with machine. Smart phone device is the interface. This will allow the challenging people to move freely without the assistant of others. They will get a moral support to live independently. The hardware used are Arduino kit, Microcontroller, Wheelchair and DC motors. DC motor helps for the movement of wheel chair. Ultra Sonic Sensor senses the obstacles between wheelchair and its way.

Keywords: Android Application, DC Motors, HC-05 Bluetooth Module, Ultra sonic Sensor, Wheel chair.
\end{abstract}

\section{INTRODUCTION}

It is an Android based application with a voice recognition system. There are many persons who are living with disabilities. It help the handicapped people to improve their live style. They can live independently and can move to and fro from one place to others by using this voice controlled wheel chair. The manual operation of wheelchair with their hands will make them tiring. So it is need of time to operate a motorized wheelchair which can be controlled by voice commands. The cost of this motorized wheelchair is affordable for many handicapped people.

\section{PROPOSED SYSTEM}

The proposed system is an automated wheelchair system with real time herald avoidance capability. It is controlled by using the android application and user's voice.

Revised Manuscript Received on January 30, 2020.

* Correspondence Author

R. Mohana Priya*, Asst. Prof Gr. II, Department of ECE, Aarupadai Veedu Institute of Technology, Vinayaka Mission's Research Foundation, Salem,Tamilnadu,India, Email:mohanapriya@avit.ac.in

Indhulekha.B U.G Student, Department of ECE, Aarupadai Veedu Institute of Technology, Vinayaka Mission's Research Foundation, Salem,Tamilnadu,India.

Riya Johnson, U.G Student, Department of ECE, Aarupadai Veedu Institute of Technology, Vinayaka Mission's Research Foundation, Salem,Tamilnadu,India.

Arun.V.N, U.G Student, Department of ECE, Aarupadai Veedu Institute of Technology, Vinayaka Mission's Research Foundation, Salem,Tamilnadu,India.

R. Karthikeyan, Department of Electronics and Communication Engineering, Aarupadai Veedu Institute of Technology, Vinayaka Mission's Research Foundation, Paiyanoor, India.

(C) The Authors. Published by Blue Eyes Intelligence Engineering and Sciences Publication (BEIESP). This is an open access article under the CC-BY-NC-ND license http://creativecommons.org/licenses/by-nc-nd/4.0/
The important aim of the proposed system is to give a healthy living style to physically challenged person. This project is divided into two parts software and hardware. Android phone is used as an intermediary for input human voice. In this project, Arduino kit (ATMEGA 328) is utilized as controller to control the forward and backward development of wheelchair. Input is human voice. There are five basic movements of a wheelchair. The Five operations perform by the wheelchair are as following:

1] Moving forward

2] Moving backward

3] Turning to the right

4] Turning to the left

5] Stop condition

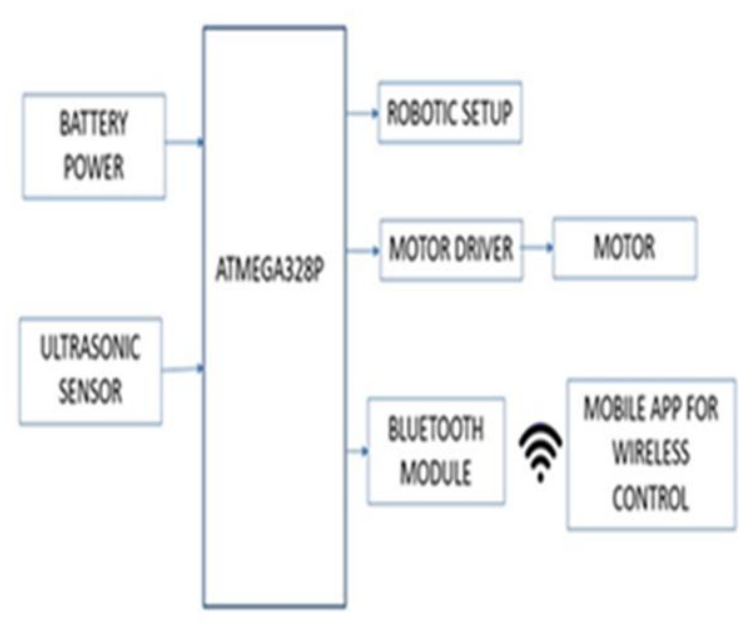

Fig1: Block diagram of proposed system

A. Battery power

A $12 \mathrm{~V}$ rechargeable battery is used in this project.

B. Microcontroller

ATMEGA-328 is basically an Advanced Virtual RISC (AVR) micro-controller.

\section{Ultrasonic Sensor}

Ultrasonic sensors which otherwise called receivers in some cases chip away at a rule same starting at a radar, which assess properties of an objective by translating the echoes. Ultrasonic sensors produce some high recurrence sound waves and assess the reverberation which is gotten back by the sensor. Sensors compute the time interim between sending the signal and accepting the reverberation to decide the separation to a hindrance.

\section{Bluetooth module}

HC-05 module is a Bluetooth SPP module that is calculated for translucent wireless sequential connection system.

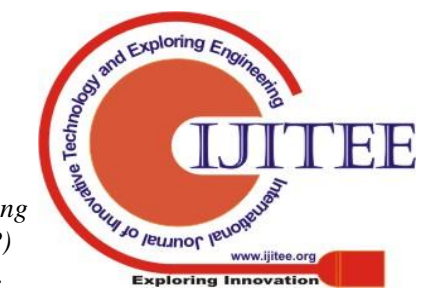




\section{Android Based Voice Activated Wheel Chair for Disabled}

\section{E. Motor Driver}

L298N 2A Based Motor Driver is used for driving DC Motors and Stepper Motors. It can regulate onboard $5 \mathrm{v}$ regulator .It controls up to $4 \mathrm{~V}$ DC motors.

\section{F. DC Motor}

In this project 4 electric dc motors. It converts electric energy into mechanical energy. A mechanical force is experienced when a current carrying conductor is placed in a magnetic field.

\section{RESULT \& DISCUSSIONS}

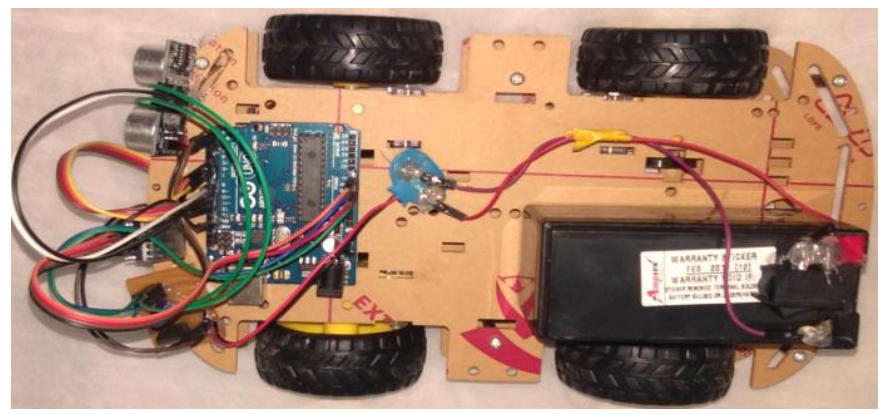

Fig.2: Implemented project prototype

The project was tested for the movement of the wheel chair using trained voice after the planning and development of the self-automated wheel chair with its various interfacing units. On the idea of two important aspects, firstly, on the accuracy of the voice system and secondly, wheelchair velocity by means of control commands this design is experimented. This would be implemented for disabled people. Various studies resulted with independent mobility or movement of disabled person by the assistant of wheelchair.

\begin{tabular}{|c|c|}
\hline VOICE COMMAND & ACTION \\
\hline GO-AHEAD & $\begin{array}{c}\text { This command will move the } \\
\text { wheelchair in forward direction. }\end{array}$ \\
\hline GO-BACK & $\begin{array}{c}\text { This command will move the } \\
\text { wheelchair in backward direction. }\end{array}$ \\
\hline TURN RIGHT & $\begin{array}{c}\text { This command will move the } \\
\text { wheelchair in right direction. }\end{array}$ \\
\hline TURN LEFT & $\begin{array}{c}\text { This command will move the } \\
\text { wheelchair in left direction. }\end{array}$ \\
\hline STOP & Wheelchair will stop its movement. \\
\hline
\end{tabular}

\section{ADVANTAGES}

> As we have discussed earlier to provide free movement for disabled and aged person.

$>$ Easy to operate.

$>$ System is simple

$>$ Monitoring of wheelchair is wireless based.

$>$ Human assistant is reduced.

$>$ Low power consuming.

A Command is given using a voice recognition system to control the movement. As discussed earlier Microcontroller ATMEGA328 and DC motor are utilized. This system proves to be more advantageous. In future high speed can be increased by using gear box. PWM modulation is employed for increasing the speed of wheelchair. Solar Panel can be deployed for charging the battery which supplies power to components connected in wheelchair.

\section{CONCLUSION AND FUTURE SCOPE}

Finally it is conclude this wheelchair will helps to minimize the manpower .

\section{REFERENCES}

1. Chin-Tuan Tan and Brian C. J. Moore, "Perception of nonlinear distortion by hearing-impaired people"," International Journal of Ideology" 2008, Vol. 47, No. 5, Pages 246-257.

2. C. M. Higgins and V. Pant," Biomimetic VLSI sensor for visual tracking of small moving targets", "IEEE Transactions on Circuits and Systems”, vol. 51, pp. 2383-2394, 2004.

3. Pacnik, G. ; Benkic, K. ; Brecko, B, "Voice operated intelligent wheelchair - VOIC", ISIE, IEEE 2005, vol.3, pp.1221 - 1226.

4. O. Majadalawieh, "On the design of a voice-controlled robotic system using HTK", Master of Applied Science Thesis, Dalhousie University Halifax, Nova Scotia, Canada. 2004.

5. Mohammad Ilyas Malik1 , Tanveer Bashir2 , Mr. Omar Farooq Khan," Voice Controlled Wheel Chair System “,'International Journal of Computer Science and Mobile Computing”, Vol.6 Issue.6, June- 2017, pg. 411-419 (C) 2017.

\section{AUTHORS PROFILE}

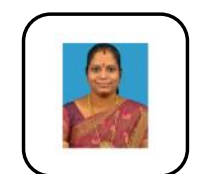

R. Mohana Piya has received her B.E. Degree in Electronics and Communication Engineering from University of Madras, Tamilnadu in 2004.M.E Degree in Applied Electronics from VMRF in 2010.She is pursuing her Ph.D in the field of Image Processing. She has been working as Assistant Professor in Department of Electronics and Communication Engineering at AVIT. Her research areas includes Image Processing, Signal Processing and Embedded Systems. She is life member of IETE since 2008: mohanapriya@avit.ac.in.

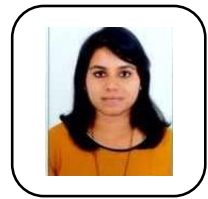

Indhulekha.B is U.G student of Department of Electronics and Communication Engineering studying Aarupadai Veedu Institute of Technology, VMRF .She is interested in doing research in Embedded Systems and Wireless Communication.

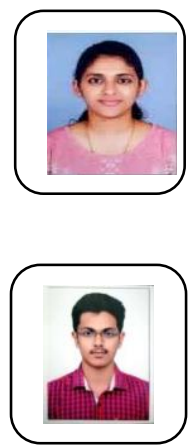

Riya Johnson is U.G student of Department of Electronics and Communication Engineering studying Aarupadai Veedu Institute of Technology, VMRF .She is interested in doing research in Embedded Systems and Wireless Communication.

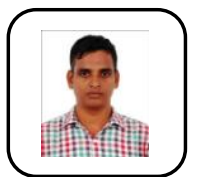

Mr. R. Karthikeyan received his B. E degree in Electrical and Electronics Engineering from Vel's Srinivasa College of Engineering and Technology, Anna University, Tamilnadu in 2006. M. E. Degree in Embedded System Technology from Aarupadai Veedu Institute of Technology, Vinayaka Mission's Research Foundation (VMRF), 2008. Pursuing his Ph. D in the field of Power Quality at VMRF. His research areas include Power Quality and data interpretation. He is life member in ISTE since2008, life member in BES since 2010, member IEEE. Mail: rrmdkarthikeyan@gmail.com.

Published By:

Blue Eyes Intelligence Engineering

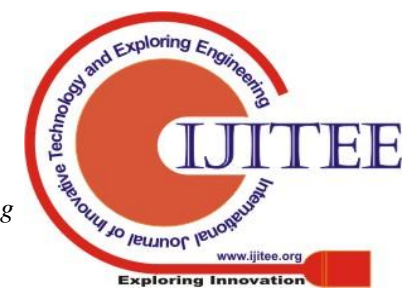

